\title{
A new GP with special interest headache service: observational study
}

\author{
Leone Ridsdale, Jane Doherty, Paul McCrone, Paul Seed \\ and the Headache Innovation and Evaluation Group
}

\begin{abstract}
Background

There is poor access to neurology services for patients in the community.

Aim

To describe the training of GPs with special interest (GPwSI) in headache and the setting up of a GPwSI clinic in general practice, and report on a comparison with the existing neurology service in terms of case severity, patient satisfaction, and cost.

Design of study

New service provision and evaluation by a questionnaire survey.

Setting

General practice and hospital neurology service in inner-city London.

\section{Method}

The intervention involved training GPs as GPwSls and setting up a GP headache service. A questionnaire survey was conducted, measuring headache impact, satisfaction, and cost estimates.

\section{Results}

Headache impact was not significantly different between the two groups of patients, referred to hospital and to a GPwSI. Patients were significantly more satisfied with the GPwSI service, particularly that the service was effective in helping to relieve their symptoms (89\% versus $76 \%$; adjusted odds ratio = $7.7 ; 95 \%$ confidence interval $=2.7$ to 22.4 ). The cost per first appointment was estimated to be $£ 136$, with $£ 68$ for subsequent contacts. These are lower than costs for neurologist contacts.

\section{Conclusion}

GPwSI services can satisfy the needs of patients with similar headache impact at costs that are lower than those for secondary care services.
\end{abstract}

\section{Keywords}

general practitioner with special interest; headache; healthcare economics; neurology.

\section{INTRODUCTION}

Gaining access to diagnosis and management for common neurological problems is not easy in the UK. ${ }^{1}$ A major reason for this is that there are fewer neurologists than in other western countries. The order of difference is large; most other European countries have 5-10 times as many neurologists to meet the needs of similar populations. ${ }^{2}$

An additional consequence of few neurologists has been that there have been too few neurology teachers to train clinical medical students and junior doctors, who have insufficient training in diagnosis and management. Consequently, doctors express lack of competence and confidence in managing common neurological problems like epilepsy and headache.,4 Fear of clinical neurology by doctors outside neurology amounts to 'neurophobia'. Neurophobia and lack of neurologists puts patients in double jeopardy.

Headache is the most common problem reported, affecting $91 \%$ of males and $96 \%$ of females at some point in their lifetime. ${ }^{6}$ In Denmark, headache and migraine account for $20 \%$ of work absence. ${ }^{7}$ Headache and migraine are in the top 10 international causes of disability. ${ }^{8}$ Despite this level of disability and work loss, most patients self-manage with over-the-counter medication, and some develop

L Ridsdale, PhD, FRCP, FRCGP, senior lecturer in neurology and reader in general practice, Unit of Neurology and General Practice, Department of Clinical Neuroscience; P McCrone, $P h D$, reader in health economics, Institute of Psychiatry; $P$ Seed, MSc, CStat, lecturer in medical statistics, Department of General Practice and Primary Care, King's College London, London. J Doherty, MRCGP, GP principal, Princess Street Group Practice, London.

Address for correspondence

Dr Leone Ridsdale, Unit of Neurology and General Practice, Department of Clinical Neuroscience, PO 41, Institute of Psychiatry, King's College London - Denmark Hill Campus, London, SE5 8AF. E-mail: L.Ridsdale@iop.kcl.ac.uk

Submitted: 23 November 2007; Editor's response: 16 January 2008; final acceptance: 26 March 2008. (c)British Journal of General Practice 2008; 58: 478-483. DOI: 10.3399/bjgp08X319440 
medication overuse. In an analysis of records from UK general practice, it was found that only $4 \%$ of registered adults present to their GP for headache and migraine each year. ${ }^{9}$ Of these, $97 \%$ were managed by GPs without referral to specialists, $2 \%$ were referred to neurologists, and $1 \%$ to other specialists.

Even with this low level of consulting and referral for headache, its high prevalence compared with other neurological conditions makes headache the most frequent reason for new referral to neurologists. ${ }^{10}$ Referral is not necessarily related to the severity or impact of the headache, ${ }^{11}$ but seems to be triggered by patient pressure. ${ }^{4}$ At least onethird of patients remain unsatisfied..$^{12}$ In the context of a scarce supply of neurologists, high demand created by headache referrals reduces access to neurologists for other conditions like epilepsy, Parkinson's disease, and multiple sclerosis.

In 2000 the British Association for the Study of Headache, a national headache interest group including specialists and GPs, proposed that many headache referrals could be managed by GPs who had undertaken additional training in headaches. ${ }^{13} \mathrm{~A}$ joint initiative between the Department of Health and the Royal College of General Practitioners agreed a template for training GPs with a special interest in headache. ${ }^{14}$

In a project based in inner-city London, this study planned to: recruit and train GPs in headache diagnosis and management; encourage GPs with special interest (GPwSIs) to contribute to headache learning among their colleagues, including GP registrars, local GPs, and GP tutors responsible for teaching clinical medical students; set up an intermediate care headache service staffed by a GPwSl; and evaluate the change, comparing case severity and patient satisfaction between a patient group referred to neurologists and to the GPwSI. ${ }^{15}$ In addition, the study compared the unit cost of contacts with the GPwSI and contacts with neurologists.

\section{METHOD}

\section{The intervention}

Training. The training consisted of: six half-day sessions of didactic teaching and included: clinical neuroanatomy, neuroradiology, neuropathology, neurology history-taking, and the management of 12 common problems such as headache; 12 sessions of clinics with a neurologist in which GPs gained confidence and competence in taking a neurological history and examination; 12 sessions of clinics with a second doctor whose special interest was headache; six sessions of clinics with other neurologists in the locality, so as to facilitate future partnerships and

\section{How this fits in}

In the past doctors have received little training in neurology and patients have had poor access to specialists. The UK Department of Health has advocated the development of services that provide better patient access by practitioners with special interest and training. GPs were trained in headache, and a headache service was set up, as well as providing additional learning for their colleagues. The patients referred to the new service had equal case severity; they were more satisfied with the service, and it was provided at a lower cost than hospital referrals.

good communication from primary to secondary care; conferences, courses, textbook and journal reading; and reflection on learning, planning how to apply learning in practice, and the writing of a learning portfolio.

A GPwSI service. Five GPwSls were trained. Each agreed to provide a service for patients in their own practices. Four GPwSIs were already trainers and/or clinical student teachers and included headache teaching in their portfolio of topics. In 2005, undergraduate GP tutors attached to the local medical school agreed to teach approximately 450 students per year in pairs using their own patients with headache, for the neurology rotation. The GPwSIs offered 'teaching the teachers' sessions for the tutors; they also provided teaching to local GPs, foundation-year doctors, and registrars.

In 2005, a GPwSI started working one session on alternative weeks, providing a GPwSI clinic. GPs were asked to refer patients with no symptoms or signs that suggested the headache was secondary in origin, with 'red flag' symptoms specified. ${ }^{16}$ The new service was offered as one option to GP referrers, who retained the option to refer any patient with headache to the hospital neurology service. During the first year of the new service being set up, an increasing number of new headache referrals were made to the clinic. In response to an audit undertaken with the primary care trust (PCT), GPs expressed willingness to refer and satisfaction with the service provided. In the second year, case severity, satisfaction, and costs were measured.

Questionnaire survey. A total of 211 consecutive patients with headache were sent a postal questionnaire after they had either attended a specialist or the GPwSI service. The questionnaire included the Headache Impact Test (HIT-6), ${ }^{17}$ and a patient General Satisfaction Questionnaire. ${ }^{18}$ HIT-6 is a valid and reliable six-item questionnaire designed to assess the impact headaches have on an individual's ability to function. Each question is on a five-point Likert scale. Six items are summed 
(possible range $=36-78$ ), and each is measured on a scale anchored at never $=6$ and always $=13$. A score above 56 is considered clinically important. Impact scores can be graded where a score $\leq 49=$ little or no impact, 50-55 = some impact, 56-59 = substantial impact, $\geq 60$ = very severe impact.

The General Satisfaction Questionnaire consists of 20 items scored on a four-point scale with a maximum possible satisfaction score of 80 . Responses include general satisfaction with the service received, satisfaction with access to services, satisfaction with the help given, and satisfaction with the acceptability of the service. Results were adjusted for age, sex, and ethnicity. Where proportions of patients who were 'satisfied' are reported, satisfaction was categorised as 3 or 4 on the scale.

The GPwSI cost per hour was estimated by dividing the total running cost by the number of hours of service provided. The running costs were based on the salary paid to the GP plus costs related to management, administration, overheads, and supervision. This information applied to the service as it was provided in north Southwark. Further cost estimates were made that applied to

\section{Table 1. Rate of satisfaction of patients with headache with 19 aspects of medical service received: comparison of patients seen by a GPwSI and a hospital neurology outpatient clinic. ${ }^{2}$}

\begin{tabular}{|c|c|c|c|}
\hline & $\begin{array}{c}\text { GPwSI } \\
\text { group }(n=61) \\
n(\%)\end{array}$ & $\begin{array}{c}\text { Consultant } \\
\text { group }(n=56) \\
n(\%)\end{array}$ & $\begin{array}{c}\text { AOR } \\
(95 \% \mathrm{Cl})\end{array}$ \\
\hline Satisfied with service & $50(82)$ & $41 / 55(75)$ & $2.4(0.97$ to 5.7$)$ \\
\hline Overall rating of service & $59(97)$ & $48 / 53(91)$ & $2.3(0.84$ to 5.4$)$ \\
\hline First reception by staff & $59(97)$ & $50(89)$ & 2.0 (0.71 to 5.8$)$ \\
\hline Manner of staff on phone & $45 / 52(87)$ & $41 / 52(79)$ & $2.0(0.74$ to 5.4$)$ \\
\hline Did you get the service you wanted? & $58 / 60(97)$ & $45(80)$ & 3.5 (1.4 to 8.8$)$ \\
\hline Relief of symptoms & $51 / 57(89)$ & $41 / 54(76)$ & 7.7 (2.7 to 22$)$ \\
\hline Help with other problems & $48 / 55(87)$ & $45 / 50(90)$ & 1.3 (0.48 to 3.5$)$ \\
\hline Would recommend to a friend & $59(97)$ & $47 / 53(89)$ & 2.0 (0.81 to 4.8$)$ \\
\hline Doctor competent and knowledgeable & $60 / 60(100)$ & $52 / 53(98)$ & $1.8(0.60$ to 5.1$)$ \\
\hline Doctor listened and understood & $57(93)$ & 49/54 (91) & 3.2 (1.2 to 8.2 ) \\
\hline Amount of help received & $55 / 60(92)$ & $44(79)$ & 3.4 (1.4 to 8.3$)$ \\
\hline Services effectively dealt with problem & $52 / 58(90)$ & $36 / 54(67)$ & 3.3 (1.3 to 7.8$)$ \\
\hline Would you go back & $58(95)$ & $52(93)$ & $1.9(0.77$ to 4.6$)$ \\
\hline Range of activities & $52 / 57(92)$ & $40 / 46(87)$ & 3.7 (1.3 to 11$)$ \\
\hline Delay in getting appointment & $59(97)$ & $39 / 54(72)$ & 10.7 (3.4 to 34$)$ \\
\hline Wait to be seen at appointment & 57 (95) & $47 / 54(87)$ & 8.7 (2.7 to 28$)$ \\
\hline Staff work as a team & $56 / 59$ (95) & $50 / 53(94)$ & 1.8 (0.73 to 4.4$)$ \\
\hline Ease of access & $58(95)$ & $43 / 53(81)$ & 2.8 (1.2 to 6.8$)$ \\
\hline Services met your needs & $48 / 57(84)$ & 29/53 (55) & 4.0 (1.6 to 10.0$)$ \\
\hline
\end{tabular}

asatisfaction is defined as answering in the top two categories out of four for each question. $A O R=$ adjusted odds ratios. the service if it was provided in a wider catchment area (north and south Southwark). Costs were estimated for first appointments and follow-up contacts. This was based on the assumption that the duration of the latter was half as long as for initial visits. Training costs were not included, and the costs should be seen as those applying to the service in a 'steady state'.

Data were available on the number of patients sent for an investigation, and it was assumed that this would be a computed tomography (CT) scan. The proportion of patients receiving a scan was multiplied by the $2006 / 2007$ NHS reference cost of a scan (£101). ${ }^{19}$ For the purposes of comparison, it was assumed that the cost of a neurologist contact would be represented by the appropriate NHS reference costs for first and subsequent appointments. The costs were also compared with the indicative national tariff that commissioners would pay for neurology appointments services. ${ }^{20}$ (These are essentially prices and may not be equal to cost.)

Statistical analysis was conducted using the package Stata (version 9.2, [StataCorp LP, College Station, Texas]). For continuous measures, estimates were adjusted for age, sex, and ethnicity. For the categorical measures of clinical severity (HIT-6 categories and components), the groups were compared using ordered logistic regression, adjusting similarly. Where proportions of patients who were 'satisfied' are reported, satisfaction was categorised as 3 or 4 on the scale.

\section{RESULTS}

A total of 117 patients (55\%) responded. Fifty-six hospital attenders responded, and 61 responded from the clinic run by the GPwSI. There was no significant difference in the age (mean 41.1 years, standard deviation $[S D]=15.2$ years, versus mean 38.3 years, $\mathrm{SD}=2.78$ years; $P=0.2$ ) or in the proportion of each sex $(57 \%$ female versus $53 \%$ female; $\chi^{2}=0.54 ; P=0.77$ ) of responders versus non-responders respectively.

There was no significant difference in headache impact between hospital (mean score 61.2, SD = 10.4) and GPwSI clinic attenders (mean score 64.3, $\mathrm{SD}=9.3$ ), after adjustment for age, sex, and ethnicity, mean difference $=2.7 ; 95 \%$ confidence interval $[\mathrm{Cl}]=1.6$ to 7.0 ). There was no measurable difference in the frequency of severe headache pain between the groups (adjusted odds ratio [AOR] = $1.05 ; 95 \% \mathrm{Cl}=0.47$ to 2.32 ), or in how often headaches limited their daily activities (adjusted OR $=1.57 ; 95 \% \mathrm{Cl}=0.72$ to 3.41 ).

The hospital clinic group had satisfaction scores of $60.2(\mathrm{SD}=7.6$ ) of the possible maximum of 80 , and the GPwSI clinic group $64.2(\mathrm{SD}=6.2)$; difference 5.7 
Table 2. Estimated costs of running the headache service for 1 year.

\begin{tabular}{|c|c|c|c|c|}
\hline Item & Person & $\begin{array}{l}\text { Cost per hour/ } \\
\text { session }(£)\end{array}$ & Sessions & $\begin{array}{c}\text { Cost per } \\
\text { year, } £\end{array}$ \\
\hline GP clinic session & GPwSI & $\begin{array}{c}250 \text { per } \\
\text { 3-hour session }\end{array}$ & $\begin{array}{l}23 \text { sessions per } \\
\text { year }(250 \times 23)\end{array}$ & 5750 \\
\hline Management costs & PSGP & 14.75 per hour & $\begin{array}{l}2 \text { hours per week } \\
(14.75 \times 2 \times 52)\end{array}$ & 1534 \\
\hline Administrator costs & PSGP & 11.35 per hour & $\begin{array}{l}2 \text { hours per week } \\
(11.35 \times 2 \times 52)\end{array}$ & 1180 \\
\hline Reception costs & PSGP & 8.00 per hour & $\begin{array}{l}2 \text { hours per clinic } \\
(8 \times 2 \times 23)\end{array}$ & 368 \\
\hline $\begin{array}{l}\text { Overheads, fax, phone, stationery, } \\
\text { and secretary }\end{array}$ & PSGP & & & 2000 \\
\hline Clinical management & PSGP GPwSI & 250 per session & 4 sessions per year & 1000 \\
\hline Clinical supervision GPwSI & GPwSI & 250 per session & 6 sessions per year & 1500 \\
\hline Clinical supervision & Consultant neurologist & 250 per session & 6 sessions per year & 1500 \\
\hline Total (including contingency) & & & & 16735 \\
\hline
\end{tabular}

(95\% $\mathrm{Cl}=2.1$ to 9.3 , adjustment for age, sex and ethnicity; $P=0.002$ ). In the hospital group, $75 \%$ of patients were either mostly or completely satisfied overall, compared with $82 \%$ of the GPwSI group (AOR $=2.4,95 \% \mathrm{Cl}=0.97$ to 5.7). Members of the group attending the GPwSI headache clinic were more often satisfied in all 19 questions, significantly so in 10 questions (Table 1).

Specifically, the patients who saw the GPwSI were more likely to report having been satisfied with the following: the waiting time between asking to be seen and being seen; the waiting time at the appointment; the ease of access to the service; that the doctor listened to and understood their problem; the amount of help they had received; the extent to which their needs were met; that the service was effective in helping to relieve their symptoms; and that the service had helped them to deal more effectively with their problems. Overall, members of this group were more likely to endorse that it was the kind of service they wanted $(97 \%$ versus $80 \%$, $\mathrm{AOR}=3.5 ; 95 \% \mathrm{Cl}=1.4$ to 8.8 ).

\section{Costs of service models}

The estimated annual costs of running the GPwSI clinic are shown in Table 2. In the year from October 2006, 102 appointments were for new patients and 42 for existing patients. The cost per hour was estimated to be £272. Assuming 30 minutes for a first appointment and 15 minutes for a follow-up, this results in costs of $£ 136$ and $£ 68$ respectively.

By comparison, the cost of neurology appointments nationally (derived from 2006/2007 NHS reference costs) are £203 (interquartile range $£ 132-239)$ for first appointments, and £121 (interquartile range £80-140) for follow ups. In $2007 / 2008$, the indicative national tariff for neurology referrals is $£ 177$ for first appointments and $£ 100$ for follow-up appointments.

If the GP costs per session increased from $£ 250$ as shown in Table 2 to $£ 350$, to reflect a higher level of seniority or experience, then the total annual cost would be $£ 19035$. This would increase the cost of first attendances to $£ 155$ and follow-ups to $£ 75$.

Nineteen patients received a scan (one of these was a magnetic resonance imaging but this was costed at the same rate as a CT) at a total cost of $£ 1919$. If this is averaged across new patients the cost per new patient increases to $£ 155$. It can be assumed that CT scans are not applied to patients attending for follow up, hence the cost for these remains at $£ 68$. There are no national data on the frequency of imaging undertaken by neurologists for headache. In practice, there is much variation in rates of referral for imaging. Preliminary evidence suggests that the GPwSI is less likely to use these tests in the management of chronic headache.

\section{DISCUSSION}

\section{Summary of main findings}

GPwSls in headache were trained, and encouraged to contribute headache teaching for: GP tutors of medical students, GPs in the locality, and GP registrars. An intermediate headache service was set up and GPs were invited to refer patients with primary headache. It was found that the group referred to the GPwSI had similar levels of headache impact as the group referred to neurologists. The group of patients referred to the GPwSI reported more satisfaction with the intermediate-level service, describing it as more 
the kind of service they wanted. The new service was cheaper than the tariff charged by hospitals.

\section{Strengths and limitations of the study}

The study was funded as part of a service innovation with evaluation, so this evidence is not as strong as that provided by a trial. However, it does demonstrate feasibility, a comparison of satisfaction, and cost in actual service conditions. There were also limitations with the assessment of economic costs. Extra training costs were not included and robust data were lacking on the use of scans.

\section{Comparison with existing literature}

The need to expand the number of neurologists is recognised, ${ }^{2}$ as is the need for more education and training for all doctors in common neurological problems. ${ }^{20,21}$ The number of neurologists is expanding, but so are demands for early diagnosis and treatment for other common neurological problems like epilepsy, Parkinson's disease, and multiple sclerosis. ${ }^{1}$ Increasing demand for services is partially patient led, but it is also a consequence of guidelines generated by the National Institute of Health and Clinical Excellence and government policy. ${ }^{22}$ In this context, it is worthwhile identifying tasks that can be undertaken by other clinicians, such as GPs and practitioners with additional training and interest.

Primary headache is the most common neurological problem. It is frequently chronic and associated with considerable disability and absence from work. Patients who are referred to neurologists are likely to worry more and to report that their headache symptoms make them more anxious. ${ }^{11}$ They link more symptoms which they relate to their headaches, and consult more frequently. ${ }^{11}$ Some patients with chronic headache may have somatisation disorder, which requires a multidisciplinary approach..$^{23}$ It is not surprising that there is dissatisfaction reported with headache management provided by general neurology clinics. ${ }^{12}$

The present study found that groups of patients with headache had similar symptom severity. Two-thirds of patients seen by the GPwSI were diagnosed with chronic daily headache (headache on 15 days per month or more), and one-third had migraine, with headache occurring less than 15 days per month. Diagnosis after the consultation for hospital referrals was not recorded in this study. Nevertheless, a prior report in the same locality found the same 2:1 ratio. ${ }^{24}$ This is the first evaluation of satisfaction with GPwSIrun headache clinics, and patients were more satisfied than with hospital referrals. Where satisfaction with a GPwSI dermatology service was measured, this also satisfied patients more than hospital services. ${ }^{24}$
The service was cheaper to run if compared to NHS reference costs or the indicative national tariff for neurology. This is in contrast to an evaluation of a GPwSI-led dermatology service. ${ }^{25}$ That particular study used a relatively low cost for specialist contacts (£47), which is less than the national tariff for dermatology outpatient contacts, even after taking inflation into account. This was because many of the specialist appointments in that trial were provided by specialist registrars in training, whose salaries are unsurprisingly lower than those of either specialists or GPs. ${ }^{24}$ (This of course may be the case with headache services.)

\section{Implications for future research and clinical practice}

The NHS now plans an 18-week pathway from referral to the start of treatment. ${ }^{22}$ Local PCTs for this study have set up a neurology clinical workstream group to manage this. Neurologists and GPs in the group agree that expanding the GPwSI service to cover two PCTs may help patients with headache, and free up capacity for patients with other neurological problems. One of the GPwSls in this study has written a checklist to help headache management across the interface between primary and secondary care. The innovation is evolving and national policy changes make evaluation difficult; nonetheless the authors believe there is room for cautious optimism.

This approach, adapted to suit the context of other localities, could help patients with neurological problems get more services that are appropriate to their needs, satisfactory, and provided at lower cost. These services require evaluation, ideally both qualitative and quantitative, to inform plans for future service change that include increased training and community services in neurology.

\section{Funding body}

Guy's and St. Thomas' Hospital Charity funded the project (G020710)

\section{Ethical approval}

Research ethics approval was obtained from the Guy's Research Ethics Committee and Southwark PCT research and development centre (03/06/12)

\section{Competing interests}

The authors have stated that there are none

\section{Acknowledgements}

The Headache Innovation and Evaluation Group included: Drs L Clarke, R Das, A Dowson, J Ferguson, B Marsh, $S$ Hunt, and T Steiner. We thank all the patients who took part in the project.

\section{Discuss this article}

Contribute and read comments about this article on the Discussion Forum: http://www.rcgp.org.uk/bjgp-discuss

\section{REFERENCES}

1. Neurological Alliance. Getting the best from neurological services. London: Neurological Alliance, 2006. 
2. Association of British Neurologists. Acute neurological emergencies in adults. London: Association of British Neurologists, 2002.

3. Thapar AK, Stott NC, Richens A, et al. Attitudes of GPs to the care of people with epilepsy. Fam Pract 1998; 15(5): 437-442.

4. Morgan M, Jenkins L, Ridsdale L. Patient pressure for referral for headache: a qualitative study of GPs' referral behaviour. Br J Gen Pract 2007; 57(534): 29-35.

5. Ridsdale L, Massey R, Clark L. No more neurophobia: making neurology teaching accessible to medical students. Pract Neurol 2007; 7(2): 116-123.

6. Silberstein SD, Lipton RB. Epidemiology of migraine. Neuroepidemiology 1993; 12(3): 179-194.

7. Rasmussen BK, Jensen R, Olesen J. Impact of headache on sickness absence and utilisation of medical services: a Danish population study. $J$ Epidemiol Community Health 1992; 46(4): 443-446.

8. Stovner LJ, Hagen K, Jensen R, et al. The global burden of headache: a documentation of headache prevalence and disability worldwide. Cephalalgia 2007; 27(3): 193-210.

9. Latinovic R, Gulliford M, Ridsdale L. Headache and migraine in primary care: consultation, prescription, and referral rates in a large population. Neurol Neurosurg Psychiatry 2006; 77(3): 385-387.

10. Patterson VH, Esmonde TFG. Comparison of the handling of neurological outpatient referrals by general physicians and a neurologist. Neurol Neurosurg Psychiatry 1993; 56(7): 830.

11. Ridsdale L, Clark L, Dowson A, et al. How do patients referred to neurologists for headache differ from those managed in primary care? $B$ Gen Pract 2007; 57(538): 388-395.

12. Fitzpatrick RM, Hopkins AP, Harvard-Watts O. Social dimensions of healing: a londitudinal study of outcomes of medical management of headaches. Soc Sci Med 1983; 17(8): 501-510.

13. British Association for the Study of Headache. Review of the organisation of headache services in primary care and recommendations for change. London: British Association for the Study of Headache, 2000.

14. Department of Health. Guidelines for the appointment of general practitioners with special interests in the delivery of clinical services: headache. London: Royal College of General Practitioners, 2003.

15. Steiner TJ. Integrating headache services across the primary/secondary interface. In: Olesen J, Steiner TJ, Lipton RB (eds). Reducing the burden of headache. Oxford: Oxford University Press, 2003: 112-120.

16. O'Flynn N, Ridsdale L. Headache. In: Marshall M, Campbell S, Hacker J, Roland M. Quality indicators in general practice. London: The Roya Society of Medicine Press, 2002: 347-360.

17. Kosinski M, Bayliss MS, Bjorner JB, et al. A six-item short-form survey for measuring headache impact: the HIT-6. Qual Life Res 2003; 12(8): 963-974.

18. Huxley P, Mohamed H. Development of a General Satisfaction Questionnaire for use in programme evaluation. Soc Work Soc Sci Rev 1992; 3: 63-74

19. Department of Health. NHS reference costs 2006-07. http://www.dh.gov.uk/en/Publicationsandstatistics/Publications/ PublicationsPolicyAndGuidance/DH_08257 (accessed 15 May 2008).

20. Department of Health. Payment by results: tariff information. http://www.dh.gov.uk/en/Managingyourorganisation/Financeandplannin g/NHSFinancialReforms/DH_077279 (accessed 1 Apr 2008).

21. Association of British Neurologists. Learning about disorders of the nervous system: recommendations for UK undergraduate education. London: Association of British Neurologists, 2006.

22. The National Institute for Health and Clinical Excellence. 18 weeks Delivering the 18 week patient pathway. http://www.18weeks.nhs.uk/ (accessed 1 Apr 2008)

23. Carson AJ, Ringbauer B, MacKenzie L, et al. Neurological disease, emotional disorder, and disability: they are related: a study of 300 consecutive new referrals to a neurology outpatient department. J Neurol Neurosurg Psychiatry 2000; 68(2): 202-206.

24. Dowson A. Analysis of the patients attending a specialist UK headache clinic over a 3-year period. Headache 2003; 43(1): 14-18.

25. Coast J, Noble S, Noble A, et al. Economic evaluation of a general practitioner with special interest led dermatology service in primary care. BMJ 2005; 331(7530): 1444-1449. 